\title{
Cardiovascular Risk Factor Screening Satisfaction in the Heart of New UIm Project
}

\author{
Wobo Bekwelem, MD; Jeffrey J. VanWormer, PhD; Jackie L. Boucher, MS; and \\ Raquel F. Pereira, MS
}

\begin{abstract}
Objective: Community-based cardiovascular disease (CVD) risk factor screening programs have been used successfully in rural health improvement initiatives. However, little is known about what consumers like or dislike about them, which is a barrier to the design of future process improvements. The objective of this study was to examine the degree to which health risks and participant characteristics predicted screening satisfaction.
\end{abstract}

Design: This study utilized a cross-sectional survey design.

Setting: Data was collected as part of the broader Heart of New Ulm Project, which is a communitybased CVD prevention demonstration project based in rural Minnesota.

Participants: There were 126 randomly invited individuals from the CVD risk factor screenings, with 118 individuals who agreed to participate and had complete data available for analyses.

Methods: A multivariate logistic regression analysis was used to examine the association between demographics, lifestyle, and biometric risk factors and screening satisfaction.

Results: Twenty percent of respondents indicated some level of dissatisfaction with the screening process. Satisfied participants were more likely to be female $(O R=4.15)$, not have an optimal lifestyle $(O R=3.47)$, and have an intention to improve their lifestyle habits $(O R=3.26)$. Age, education, and CVD risk level were not significant predictors in the final model.

Conclusion: Satisfaction was high in this screening program, with healthy males being least satisfied with their experience. This has implications for the design of future intervention efforts, as they may require specific programmatic features and more specialized, targeted marketing strategies to attract a broad spectrum of participants likely to benefit.

Keywords: Cardiovascular diseases; Mass screening; Patient satisfaction; Risk factors; Rural health

$\mathrm{D}$ espite the progress in reducing cardiovascular disease (CVD) mortality over the last 40 years, ${ }^{1} \mathrm{CVD}$ incidence rates have largely remained stable in rural areas; ${ }^{2,3}$ thus there remains a need to improve control of CVD risk factors. Perhaps because rural communities generally have poorer access to primary care, ${ }^{4,5}$ community-based CVD risk factor screening programs have demonstrated some evidence of benefiting rural adults indicated for CVD preventive medical therapies (eg, aspirin, statin). ${ }^{6}$ Risk factor screenings for CVD generally involve community residents attending an event at a local community center (eg, clinic, church, school) to have their risk factors measured and receive personalized advice and/or medical referrals to improve their health. The overarching logic for such programs is that improved awareness of CVD risk factors empowers individuals to take action or receive more advanced preventive medical care.

Engaging many community residents to participate in a given CVD risk factor screening program may improve their population level impact. Individuals or groups who are 
satisfied with their experience will likely encourage others to get screened as well, thereby generating positive "word of mouth" to strengthen recruitment efforts. But the scientific literature on screening satisfaction is mostly limited to healthcare services related to disease endpoints, particularly cancer (eg, colonoscopy, mammography). And although worksite CVD risk factor screenings have recently become more common, ${ }^{7}$ very little is known about what factors drive participant satisfaction with a given program. In particular, no studies to date have examined satisfaction with rural CVD risk factor screenings. As such, the objectives of this study were to: (1) describe the level of satisfaction with a recently completed rural CVD risk factor screening program, and (2) examine the degree to which health risks and participant characteristics predicted screening satisfaction.

\section{Methods}

\section{Screening Program Description}

This study took place within the context of the broader Heart of New Ulm (HONU) Project, ${ }^{8}$ and the screening methods are described in more detail elsewhere. ${ }^{9}$ Briefly, all CVD risk factor screenings took place in various community venues (eg, worksites, community centers, churches) within the 56073 zip code area, which is a predominantly rural area surrounding the city of New Ulm, MN, about 100 miles southwest of the Minneapolis-St. Paul metropolitan area. Screenings were open to all adults over age 18 years and were offered at no charge. For any given participant, a screening was done in a single 20 to 30 minute session and included registration/consent, self-reported health survey, anthropometric data collection, venipuncture, and reporting/ coaching. The last step included a printed personal risk factor report along with a brief consultation with a health coach that included a review of risk factors, a discussion of health improvement goals, and guidance on community resources or other health education needs. All screenings occurred between mid-April to mid-December 2009. There were 109 screenings total during that time, and 5198 individuals participated.

\section{Design and Sample}

A cross-sectional research design was utilized. All screening procedures were approved by the Allina Institutional Review Board, but the measurement of participant satisfaction occurred as part of an independent program evaluation; thus no sample exclusion criteria were applied, and only aggregatelevel results were reported. The target population was all individuals who completed a CVD risk factor screening offered by the HONU Project. Specifically, 126 individuals were randomly (systematically) invited to complete the satisfaction survey. Of these, $120(95 \%)$ agreed to do so. Data from two participants were excluded from analyses because they refused all venipuncture procedures and thus did not undergo the complete screening experience; therefore, the final analytical sample included 118 individuals. The mean \pm SD age was $47.7 \pm 14.8$ years. In addition, $40 \%$ of the sample was male, and $35 \%$ had a college degree.

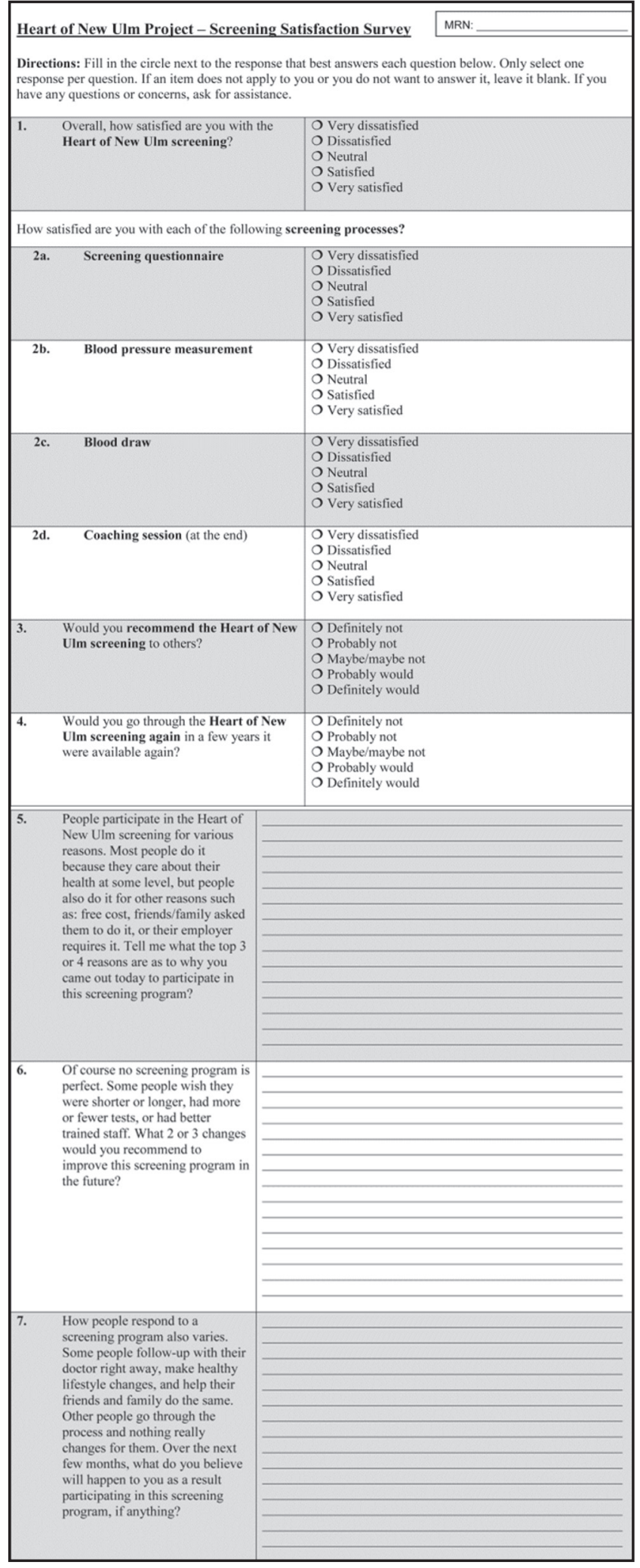

Figure 1. Screening satisfaction survey and brief qualitative interview from the Heart of New Ulm Project.

\section{Procedures}

Four screening sites administered the satisfaction survey. The sites were selected to provide a reasonably representative catchment of all screening participants. Two were large 
Table 1. Health characteristics of respondents in the Heart of New Ulm project screening satisfaction survey $(\mathrm{N}=118)$.

\begin{tabular}{ll}
\hline Health characteristics & $\mathbf{n}(\%)$ \\
\hline $\begin{array}{l}\text { Cardiovascular disease risk level } \\
\text { High risk }\end{array}$ & $12(10)$ \\
$\quad$ Less than high risk & $106(90)$ \\
Metabolic syndrome & \\
$\quad$ Present & $33(28)$ \\
$\quad$ Absent & $85(72)$ \\
Optimal lifestyle & $12(10)$ \\
$\quad$ Yes & $106(90)$ \\
$\quad$ No & $3.9 \pm 2.7$ \\
Perceived stress score (points, mean $\pm S D)$ & \\
Intention to improve lifestyle habits & $56(47)$ \\
$\quad$ Yes & $62(53)$ \\
$\quad$ Maybe or no & \\
\hline
\end{tabular}

community-oriented screenings (one at a community center and the other at the local medical center) and two were large worksite-oriented screenings (one with primarily labor occupations and the other with primarily desk occupations). The community sites were open to all adult residents and tended to attract a slightly older, higher-risk group of participants. The workplace sites were open to adult employees and spouses, and tended to attract slightly younger participants. One screening was held on a weekend and the other three on weekdays.

Following collection of each participant's screening measures, a satisfaction survey and brief face-to-face interview were administered immediately. At the beginning of each 10-minute time interval during a screening, the first individual to complete the screening and exit the site was invited to complete the satisfaction survey/interview. Selected individuals were administered the survey immediately, and it was completed within 10 minutes.

\section{Measures}

Primary dependent measures included satisfaction with the screening program. As outlined in figure 1, the screening satisfaction survey was a 10 -item questionnaire divided into two sections. The first section included seven closed-ended satisfaction questions using five-point response options. The second section was comprised of three semi-structured qualitative interview questions. This section was open-ended and sought to evaluate detailed reasons why individuals decided to participate in the screening, recommended changes to improve the screening process, and participants' intentions following the screening. Participants were encouraged to freely express their reservations or approval of the entire process. Qualitative responses were transcribed verbatim. Predictor variables were selected based on their suspected potential to influence satisfaction with the screening program. These variables were measured as part of the screening survey and included:
- Demographics - Self-reported age, sex, and education level (collapsed into college degree or no college degree).

- CVD risk level - A Reynolds Risk Score was calculated for each individual. ${ }^{10,11}$ This estimates an individual's 10-year probability of experiencing a CVD event (eg, myocardial infarction, revascularization). It takes into account age, sex, smoking, systolic blood pressure, total cholesterol, high-density lipoprotein (HDL) cholesterol, and high sensitivity C-reactive protein.

- Metabolic syndrome - Metabolic syndrome was defined as the presence of at least three of five health conditions, including: ${ }^{12}$ (1) systolic blood pressure $\geq 130 \mathrm{~mm} / \mathrm{Hg}$, or diastolic $\geq 85 \mathrm{~mm} / \mathrm{Hg}$, or current high blood pressure medication; (2) waist circumference $\geq 40$ inches (male) or $\geq 30$ inches (female); (3) HDL cholesterol $<40 \mathrm{mg} / \mathrm{dL}$ (male) or $<50 \mathrm{mg} / \mathrm{dL}$ (female); (4) triglycerides $\geq 150$ $\mathrm{mg} / \mathrm{dL}$; and (5) blood glucose $\geq 100 \mathrm{mg} / \mathrm{dL}$ or current glucose control medication.

- Optimal lifestyle - Optimal lifestyle was designated as having each of the following five characteristics: (1) non-smoker; (2) $\geq 150 \mathrm{~min} / \mathrm{wk}$ of moderate physical activity; (3) 0 to14 alcoholic drinks/wk; (4) $\geq 5$ servings of fruits/vegetables daily; and (5) body mass index (BMI) $<30 \mathrm{~kg} / \mathrm{m}^{2}$. This designation was based on previous research by Khaw et al. ${ }^{13}$

- Perceived stress - Stress was assessed using the short version of the Perceived Stress Scale. ${ }^{14}$ This included four items that capture feelings about the magnitude of life challenges as well as personal stress management abilities over the past month. An index score between 0 and 16 points is created by summing the four 4-point response options.

- Intention to change - Intention to change was assessed via a single-item question asking if participants intended to improve their lifestyle habits over the next six months. Responses were yes, maybe, or no (collapsed to yes or no/maybe).

Analysis

Each individual was assigned to one of two categories based on their response pattern to the first section of the survey. Participants who responded "satisfied", "very satisfied", "probably would", or "definitely would" to all seven questions in the first (quantitative) section of the satisfaction survey were categorized as "satisfied". All other participants were categorized as "not satisfied". Responses are often skewed in satisfaction surveys, and the dichotomization of the outcome variable in this study was done to create a more conservative characterization of screening approval. Essentially any indication of less-than-complete satisfaction, even a response of "neutral" or "maybe" on one item, was deemed "not satisfied" for analytical purposes.

The association between satisfaction and the predictor variables was examined using multiple logistic regression (PROC LOGISTIC; SAS Version 9.2, Cary, NC). All 
Table 2. Satisfaction of risk factor screening procedures in the Heart of New Ulm project $(\mathrm{N}=118)$.

\begin{tabular}{|c|c|}
\hline Screening procedure satisfaction & n (\%) \\
\hline \multicolumn{2}{|l|}{ Overall screening } \\
\hline Very satisfied & $69(58)$ \\
\hline Satisfied & $40(34)$ \\
\hline Neutral & $1(1)$ \\
\hline Dissatisfied & $1(1)$ \\
\hline Very dissatisfied & $7(6)$ \\
\hline \multicolumn{2}{|l|}{ Survey } \\
\hline Very satisfied & $54(46)$ \\
\hline Satisfied & $56(47)$ \\
\hline Neutral & $3(3)$ \\
\hline Dissatisfied & $0(0)$ \\
\hline Very dissatisfied & $5(4)$ \\
\hline \multicolumn{2}{|l|}{ Blood pressure } \\
\hline Very satisfied & $64(54)$ \\
\hline Satisfied & $44(37)$ \\
\hline Neutral & $3(3)$ \\
\hline Dissatisfied & $4(3)$ \\
\hline Very dissatisfied & $3(3)$ \\
\hline \multicolumn{2}{|l|}{ Venipuncture } \\
\hline Very satisfied & $69(58)$ \\
\hline Satisfied & 39 (33) \\
\hline Neutral & $6(5)$ \\
\hline Dissatisfied & $0(0)$ \\
\hline Very dissatisfied & $4(3)$ \\
\hline \multicolumn{2}{|l|}{ Coaching } \\
\hline Very satisfied & $64(54)$ \\
\hline Satisfied & $47(40)$ \\
\hline Neutral & $3(3)$ \\
\hline Dissatisfied & $1(0)$ \\
\hline Very dissatisfied & $3(3)$ \\
\hline \multicolumn{2}{|l|}{ Recommend screening to others } \\
\hline Definitely would & $90(76)$ \\
\hline Probably would & $25(21)$ \\
\hline Maybe/maybe not & $2(2)$ \\
\hline Probably not & $0(0)$ \\
\hline Definitely not & $1(1)$ \\
\hline \multicolumn{2}{|l|}{ Attend screening again } \\
\hline Definitely would & $86(73)$ \\
\hline Probably would & $30(25)$ \\
\hline Maybe/maybe not & $0(0)$ \\
\hline Probably not & $1(1)$ \\
\hline Definitely not & $1(1)$ \\
\hline
\end{tabular}

predictors were considered for inclusion into the final regression model. Predictors were initially entered into the model simultaneously, and manual, backwards selection criteria were applied that retained predictors with $P<0.10$. This threshold of statistical significance was used due to the exploratory nature of this study and the fact that it utilized observational data. Effect modification was not examined due to the small sample size.

Responses to the open-ended questions were analyzed using a general inductive, qualitative approach. ${ }^{15}$ Specifically, responses were jointly reviewed several times by the first and second authors, and overlapping comments were coded into agreed upon common themes (descriptive categories) that emerged based on the interview texts. From this coding scheme, the most common reoccurring themes were inductively developed that reflected participants' main attitudes toward their screening experience.

\section{Results}

Descriptive characteristics of the analytical sample are outlined in table 1 . No significant differences were observed between respondents $(n=118)$ and non-respondents $(n=6)$ (non-respondents' data not shown). As expected, satisfaction was quite high with over $90 \%$ of respondents reporting they felt very or somewhat satisfied with each of the given screening procedures (table 2). The venipuncture procedure was the least satisfying component of the screening process. Overall, 24 participants (20\%) indicated at least some level of dissatisfaction on one or more items, whereas the remaining 94 participants $(80 \%)$ indicated complete satisfaction across all items.

The final multivariate regression model revealed that the adjusted odds of being in the "satisfied" analytical category was significantly higher among participants who were female $(\mathrm{OR}=4.15$ [1.49, 11.60], $P=0.007)$, did not have an optimal lifestyle $(\mathrm{OR}=3.47[0.79,15.14], P=0.098)$, and intended to change their lifestyle $(\mathrm{OR}=3.26$ [1.08, 9.87], $P=0.036)$. The final multivariate regression model with all included beta terms and directions of associations is summarized in table 3 .

Responses to the semi-structured interview questions were grouped into four major themes, including: (1) community engagement; (2) personal health concerns; (3) financial value; and (4) peer/family support. More specifically, the most common indications associated with each theme related to why people chose to participate in the screening were (respectively): (1) "I wanted to show support for my community's project"; (2) "I care about my health"; (3) "The screening was free"; and (4) "I was strongly encouraged by my employer, friends, and/or family." The most commonly recommended changes to the screening process were: more streamlined organization of proceeding through measurement stations, more privacy during sensitive activities like weighins and coaching, and expanded days/times available for screenings. The most commonly reported behavior change intentions in response to the screening were to eat healthier, exercise more, and/or try to influence family members or friends to improve their health. However, few participants expressed certainty or extensive detail as to whether or not (or how) they would make healthy changes as a result of participating in the screening.

\section{Discussion}

Very little is known about what consumers like or dislike about community-based CVD risk factor screening programs. In the HONU Project, satisfaction with the overall screening experience was high. The general profile of participants that 
Table 3. Final multivariate logistic regression model of the association between screening satisfaction and significant predictors in the Heart of New Ulm Project ( $\mathrm{N}=118)$.

\begin{tabular}{|c|c|c|c|c|c|}
\hline \multirow[b]{2}{*}{ Model predictors } & \multicolumn{5}{|c|}{ Satisfied (vs. Dissatisfied) } \\
\hline & $\beta^{*}$ & SE & OR & Cl & $\boldsymbol{P}$ \\
\hline Intercept & -3.05 & 0.59 & --- & --- & $<0.001$ \\
\hline $\begin{array}{l}\text { Female } \\
\qquad(\text { ref = male })\end{array}$ & 1.42 & 0.52 & 4.15 & $1.49-11.60$ & 0.007 \\
\hline Optimal lifestyle, no (ref = yes) & 1.24 & 0.75 & 3.47 & $0.79-15.14$ & 0.098 \\
\hline $\begin{array}{l}\text { Intention to improve lifestyle, yes } \\
\text { (ref = maybe or no) }\end{array}$ & 1.18 & 0.56 & 3.26 & $1.08-9.87$ & 0.036 \\
\hline
\end{tabular}

were most satisfied with their screening experience was that of females with several lifestyle risk factors and an expressed intention to improve their health over the ensuing six months. The latter two predictors were perhaps most encouraging in the sense that they represent groups who were both pleased with and had a presumably high propensity to benefit from the screening (ie, poor lifestyle habits but desire to improve them). These findings conflicted somewhat with those of other studies where participants with better physical functioning and optimal lifestyle were actually more likely to be satisfied with preventive healthcare services. ${ }^{16,17}$ Others have also found that satisfaction with post-CVD medical services (some of which overlap with a CVD risk factor screening) is associated with older age and more education, ${ }^{17,18}$ but these factors were relatively weak in the current study.

In contrast, males with an optimal lifestyle were least likely to feel satisfied with their screening experience. At least some of these sentiments seemed to be due to social pressures. The HONU Project operates across the entire community, and many participants in the qualitative interview reported being strongly encouraged to take part in the screening by an employer, coworker, or family member. This seemed to be particularly predominant among married males, who often cited spousal influence as a motivation for participation. A similar reason may explain the dissatisfaction among participants who reported an optimal lifestyle, yet still spent 20 to 30 minutes going through a screening process they may have personally felt was unnecessary for them (but participated anyway due to perceived pressure from others). This phenomenon may have implications for future intervention efforts as part of the HONU Project in that more specialized, targeted marketing strategies may be needed to engage a subset of healthy males in, perhaps, a health maintenance program.

The primary limitations of this study were the cross-sectional design and the relatively small sample that had limited power to detect some associations. The sample was fairly representative of the target population of all screened individuals due to the systematic selection process and high response rate. Indeed, the distribution of participants' demographic characteristics closely mirrored those observed in the broader HONU project (data not shown); thus selection bias seemed unlikely, but widespread generalizability beyond Midwestern rural communities may be limited due to the racially homogenous nature of the study setting. The immediate administration of the satisfaction survey after screening likely helped minimize recall bias, but other measurement biases could have been at play, because most variables were self-reported and thus could have been subject to acquiescence and gratitude biases, as is sometimes found in face-to-face satisfaction interviews. ${ }^{19,20}$

\section{Conclusion}

The findings from this evaluation were encouraging overall in that the vast majority of participants from this rural community reported a high degree of satisfaction with their CVD screening experience, which occurred outside of the traditional clinic environment and workflow. In addition, despite some dissatisfaction with some procedures, only two participants indicated that they would not participate in such a screening again, if available. This overall positive sentiment may bolster future recruitment efforts in follow-up health improvement programming associated with the HONU Project. However, further investigations are needed in larger, more diverse samples to confirm the findings in this analysis and identify other predictors of satisfaction within CVD screening programs, as well as potential demographic disparities in screening participation.

\section{References}

1. Ford ES, Ajani UA, Croft JB, Critchley JA, Labarthe DR, Kottke TE, Giles WH, Capewell S. Explaining the decrease in U.S. deaths from coronary disease, 1980-2000. N Engl J Med 2007;356:2388-2398.

2. Roger VL, Jacobsen SJ, Weston SA, Goraya TY, Killian J, Reeder GS, Kottke TE, Yawn BP, Frye RL. Trends in the incidence and survival of patients with hospitalized myocardial infarction, Olmsted County, Minnesota, 1979 to 1994. Ann Intern Med 2002;136:341-348.

3. Greenlee RT, Naleway AL, Vidaillet H. Incidence of myocardial infarction in a general population: the Marshfield Epidemiologic Study Area. WMJ 2002;101:46-52.

4. MacDowell M, Glasser M, Fitts M, Nielsen K, Hunsaker M. A national view of rural health workforce issues in the USA. Rural Remote Health 2010;10:1531.

5. Colleran KM, Richards A, Shafer K. Disparities in cardiovascular disease risk and treatment: demographic comparison. J Investig Med 2007;55:415-422. 
6. Nafziger AN, Erb TA, Jenkins PL, Lewis C, Pearson TA. The Otsego-Schoharie healthy heart program: prevention of cardiovascular disease in the rural US. Scand J Public Health Suppl 2001;56:21-32.

7. Goetzel RZ, Ozminkowski RJ, Pelletier KR, Metz RD, Chapman LS. Emerging trends in health and productivity management. Am J Health Promot 2007;22:suppl 1-7, iii.

8. Boucher JL, Pereira RF, Graham KJ, Pettingill RR, Toscano JV, Henry TD. The heart of New Ulm: A vision for the future. J Cardiovasc Trans Res 2008;1:310-316.

9. VanWormer JJ, Johnson PJ, Pereira RF, Boucher JL, Britt HR, Stephens CW, Thygeson NM. The Heart of New Ulm Project: Using community-based cardiometabolic risk factor screenings in a rural population health improvement initiative. Popul Health Manag; In press.

10. Ridker PM, Buring JE, Rifai N, Cook NR. Development and validation of improved algorithms for the assessment of global cardiovascular risk in women: the Reynolds Risk Score. JAMA 2007;6:611-619.

11. Ridker PM, Paynter NP, Rifai N, Gaziano JM, Cook NR. $\mathrm{C}$-reactive protein and parental history improve global cardiovascular risk prediction: the Reynolds Risk Score for men. Circulation 2008;22:2243-2251.

12. Grundy SM, Cleeman JI, Daniels SR, Donato KA, Eckel RH, Franklin BA, Gordon DJ, Krauss RM, Savage PJ, Smith SC Jr, Spertus JA, Costa F; American Heart Association; National Heart, Lung, and Blood Institute. Diagnosis and management of the metabolic syndrome: an American Heart Association/National Heart, Lung, and Blood Institute Scientific Statement. Circulation 2005;112:2735-2752.

13. Khaw KT, Wareham N, Bingham S, Welch A, Luben R, Day N. Combined impact of health behaviours and mortality in men and women: the EPIC-Norfolk prospective population study. PLoS Med 2008;5:12.

14. Cohen S, Kamarck T, Mermelstein R. A global measure of perceived stress. J Health Soc Behav 1983;24:385-396.

15. Thomas DR. A general inductive approach for analyzing qualitative evaluation data. American Journal of Evaluation 2006;27:237-246.

16. Schutt RK, Cruz ER, Woodford ML. Client satisfaction in a breast and cervical cancer early detection program: the influence of ethnicity and language, health, resources, and barriers. Women Health 2008;48:283-302.

17. Barry LC, Lichtman JH, Spertus JA, Rumsfeld JS, Vaccarino V, Jones PG, Plomondon ME, Parashar S, Krumholz HM. Patient satisfaction with treatment after acute myocardial infarction: role of psychosocial factors. Psychosom Med 2007;69:115-123.

18. Spernak SM, Moore PJ, Hamm LF. Depression, constructive thinking and patient satisfaction in cardiac treatment adherence. Psychol Health Med 2007;12:172-189.

19. Emmons R, McCoulough M. The Psychology of Gratitude. New York, NY: Oxford University Press; 2004.

20. Campbell BB, Gosselin PA. High patient satisfaction amongst males participating in men's educational group appointments (MEGA) for routine physical exams. J Mens Health Gend 2007;4:266-270.

\section{Author Affiliations}

Wobo Bekwelem, MD*; Jeffrey J. VanWormer, PhDt; Jackie L. Boucher, MS*; and Raquel F. Pereira, MS

*Department of Medicine, University of Minnesota, Minneapolis, MN

Epidemiology Research Center, Marshfield Clinic Research Foundation, Marshfield, WI

Department of Education, Minneapolis Heart Institute

Foundation, Minneapolis, $M N$ 